\title{
PROCESSING OF DigitAL MOIRÉ IMAGES IN SALUS ORTOPÉDTECHNIKA KFT.
}

Petra Balla, Ferenc Marlok, Katalin Prommer, Szilvia Nagy, Orsolya Schulcz, Gyula Kocsis, Benjamin Magocsi

Salus Ortopédtechnika Kft.

petra.balla@mogi.bme.bu

\begin{abstract}
More and more children and youngsters are affected by spinal deformities these days. These diseases can be well cured if they are detected and filtered out in time. We wanted to set up an objective and safe method with which we can diagnose wide spectrum of school-aged youngsters without harmful side-effects. Creating moiré images was one way to solve this problem, that is the reason why we started to test this method in filtering and following the condition of our young patients. Patients measured by us were going through a general examination method where their phisical status was examined by physiotherapists, and relief images were taken of their back.

The initial aim to make the moiré image use an objective method to filter and follow the patient's condition in case of weed curvature of the spine could not be totally fulfilled. The reason is that the evaluation of the images is still a subjective method done by our vision. A possible solution could be to find an objective evaluation method where we can process, evaluate and compare the images with the same conditions. The programming and use of a proper image processing algorithm could be a great help for us.
\end{abstract}

Keywords: digital moiré, moiré evaluation, Kamal's method, moiré method

\section{Introduction}

In the Salus Kft. the digital, computer-aid moiré device is being tested for a few years. We use it especially to follow patients' conditions, but it can be used also for screening healthy patients. Originally this method would have been a substitution instead of manual examination. Unfortunately this system has not been developed yet, but we would like to improve a method.

In every 3 months children have to get their braces checked. They have to visit our company to let us take a moiré picture/image of their bodies. In this way the improvement or deterioration will be visible. Sometimes this picture can be eye-catching for children, in many cases they face their backs' condition. If somebody wears the brace carelessly and the moiré picture shows decadence the experience causes the patient to wear the brace properly. If somebody wears this device properly, 20-22 hours daily, the moiré picture generally shows some improvement. This experience could help to follow the treatment dedicated to reach the best results.

In a few cases the moiré image is not in balance with the X-ray images. Sometimes improvement was detected, however the X-ray showed unequivocal decadence. This phenomenon is attributed to the physiotherapy led by us. We have experienced the opposite way as well.

The back is left untouched by the examination, so it does not cause any exposure for young and teenage children. Moreover the number of examinations of the patient's back could be increased 
using this method. The examination is fast and quite cheap, so it can be performed any number of times.

\section{The Moiré Effect}

Optical measurement methods of three-dimensional surface metrology became rapid and effective tools especially in the field of orthopedics, ${ }^{1-5,7,17-19}$ where moiré imaging (used mostly in spinal deformities) is considered to be capable of measuring and graphically displaying whole surfaces instantaneously. ${ }^{23}$

By the superimposition of two similar periodic structures translated, or rotated relative to each other, a new structure arises with longer periods. This one is called moiré pattern and it consists of the moiré fringes.

During the moire surface measurement a grating (or its shadow) is projected to the surface of the model, where this grating will take a distorted form due to te model's shape. Another grating (which can be the same) is located between the model and the observer (that can be for example a camera or a person's eye). As the second grating remains unchanged, it can be considered as a reference grating. The axis of the observer encloses a certain angle with the axis of the projection by intersecting each other on the surface. ${ }^{30-32}$

We can find several points on the moiré pattern that have the same distance from the reference surface (or base plane). By connecting these points, contours can be created, just as at the topographical maps, in this way the test surface can be described with these lines.

By superimposing two periodic or quasi-periodic structures, the moiré phenomenon can be observed. When the two structures have the same or slightly different line spacing and their lines are set approximately parallel, a new coarse pattern appears. This pattern is known as the moiré fringe pattern. The spacing and orientation of the moiré fringes depend on the spacing and orientation of the structures being overlapped whereas the visibility of fringes is related to the width of transparent or black lines with respect to the line spacing of the structures. Moiré topographical methods can be distinguished as: the basic grating-shadow, the grating-projection, the grating-TV and the synthetic, computer generated grating methods. Shadow moire is a contour mapping technique that involves positioning a grating close to an object and observing its shadow on the object through the grating. Thus, the basic grating-shadow method offers the best accuracy and the simplest arrangement because the projected grating and the master grating are identical, so they have the highest degree of binding. The disadvantage of the shadow moiré technique is that the master grating must have similar size as the measured object.

The moiré method has several advantages, such as being fast, relatively cheap, highly sensitive, and has graphical results. It is also essential that the method offers a non-contact surface measurement ${ }^{20}$ which does not burden the patient with radiation, unlike $\mathrm{x}$-ray analysis. Moiré measurement can be a supplementary method for determining the necessary further examinations and treatments of patients.

The main advantages of the moiré technique during the quantification of spinal deformities are the simple assembly and cheap construction of the measuring device. It offers a fast and easy way 
to interpret the content of the moiré picture towards the user. The moiré fringes formed on the human back allows the examiner to find the characteristic points of the spine easily.

The masurement method can be applied in several other areas, as it offers the chance to determine deformations caused by pressure or temperature change in cases where mechanical measurement methods are not an option. The dimensional accuracy of mass production or products in robotics can also be measured with this method.

\section{The moiré equipment}

This equipment is used in the gym of Salus Ltd., it is designed and developed with help of ortophedic medicals. Actually it is a classical projection moiré equipment, ${ }^{21-22}$ but we use video projector instead of the traditional projector. We have to take a picture from the reference area first, then the patient's back appears in the examinated area. The pattern and the settings are left without change. Because of the examined object the pattern will be strained. Another photo is taken of this, and the computer ${ }^{24}$ produce a moiré picture from these data. ${ }^{33}$ The image can be evaluated with one of the previously described algorithms. In this picture the contours are visible, subjective evaluation also can be applied..$^{27-28}$

\section{Spinal Deformity Types}

Scoliosis is a weed deformity on the spine it can be visible mostly in the frontal plane. It has two different types, functional and structural scoliosis. In both cases there are weed lateral deformities on the spine, but in case of funtional scoliosis there isn't any rotation. Rib deformations cannot be observed with stoop instead of structural scoliosis, as it is hard to remark. Mostly angle of that deformity will stagnate. Physiotheraphy can be the suitable method to cure it. Asymmetrical strengthening of the back muscles is a good solution to pull weed curvatures into the right position.

It can be divided into primer and secunder scoliosis. If patients has difference between their legs, weakness in their muscles, it can be diagnosed as a secunder scoliosis. It is very important to find and cure cases for the successful treatment. Without any visible cases can be diagnosed as a primer scoliosis.

By structural scoliosis there are weed lateral deformities on the spine with torsion. Cases has not been found yet to complain the development of the disease. Dispersion is not equal between the two genders. Young girls are more often concerned compared to boys. It could be discovered in rapid growth phase of the bones, mostly at teenagers. Sadly we meet 3-4 years old little children with large deformities who have to wear the brace until the end of ossification.

Rib or chest deformations can be observed, as the result of vertebrae torsion. Patients handled by us the physiological sagittal curvatures seems to be reduced. Patients have to wear brace until the end of ossification, without this the disease will deteriorate. For teenage girls the ossification ends two years after the first menstruation. To verify it X-ray images are needed, that can show the developed Rissel mark on the pelvis. Scoliosis without treatment can cause pain, aesthetic problems, diasbility and even failures in blood circulation. 
The Cobb angle is measured on plane radiographs by drawing a line through the superior endplate of the superior end vertebra of a scoliotic curve, and another line through the inferior endplate of the inferiormost vertebra of the same scoliotic curve, and then measuring the angle between these lines. ${ }^{6,26}$

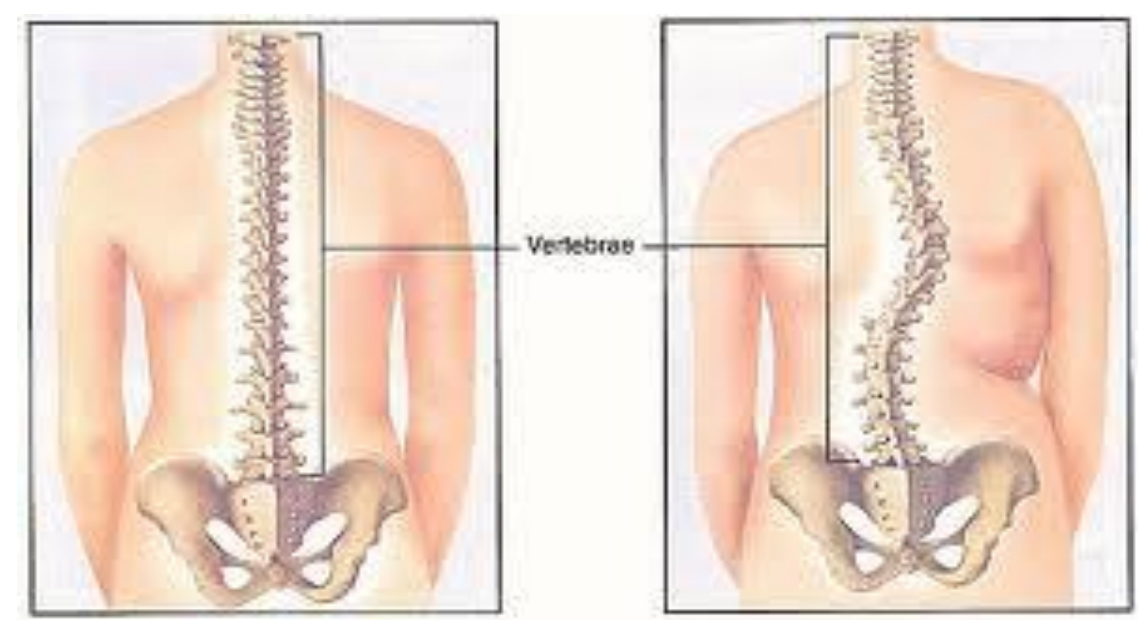

Figure 1. Scoliosis 8

The second type of spine deformity is the Scheuermann disease. At this disease the spine is straight in the frontal plane, but the kyphosis is much rounder than at healthy people. Nowadays the lumbar kyphosis is also very frequent. Often negligent posture is diagnosed instead of Scheuermann disease, and it remains without a brace and a suitable treatment. In general, shapes of vertebrae change on the inner side of spine. In case of the disease vertebrae are lower in the inner side and the collagen combination is changed in the endplates, so the cartilage rift becomes tight between vertebrae.

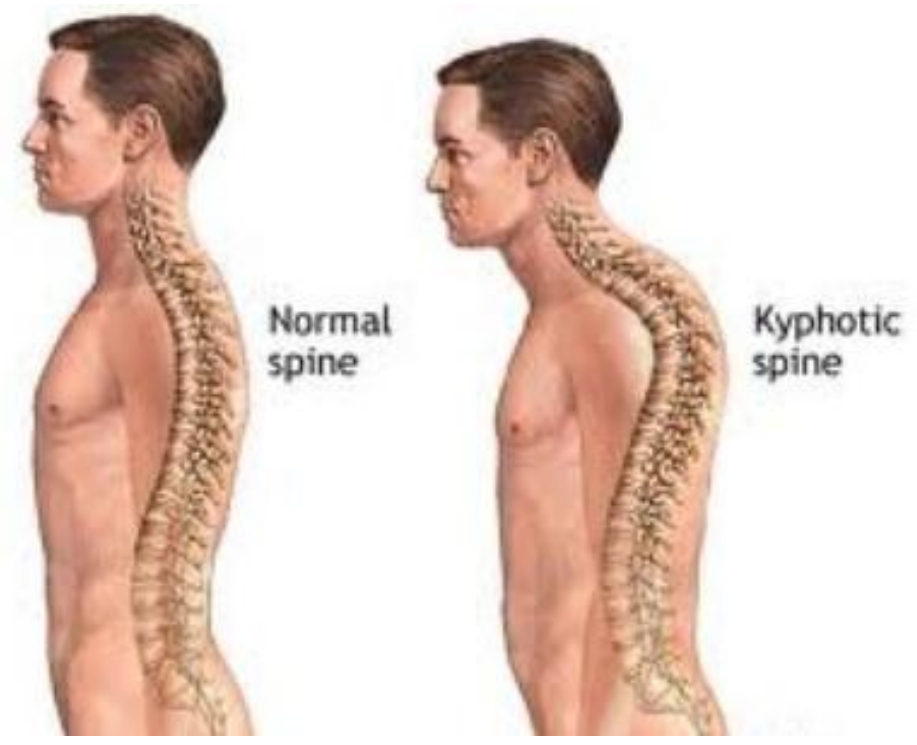

Figure 2. Scheuermann disease ${ }^{29}$ 


\section{Treatment of The Spinal Deformations}

The treatment method has to be chosen according to the condition of the disease.

Under 20 Cobb degree physiotherapy can be sufficient. During the tournament muscles are strengthen asymmetrically, so they can keep the weed curvatures in the normal position. A few special exercises have to be practiced 5 to 7 times a week to get improvement.

Between 20 and 50 Cobbs special Schroth physiotherapy have to be combined with brace treatment. The brace is a rigid, uncomfortable device. It puts pressure on the trunk to upright carriage. Opposite of this there have to be moving areas, it's because of the movement needs of the trunk. It stimulates patients to use their own muscles, as they try to get into a position where they don't feel pain. It is important to do also physiotherapy. Doing other sports (swimming for example) while wearing brace could be also effective, as muscles of the spine get stronger asymmetrically, just like with physiotherapy. ${ }^{10-15}$

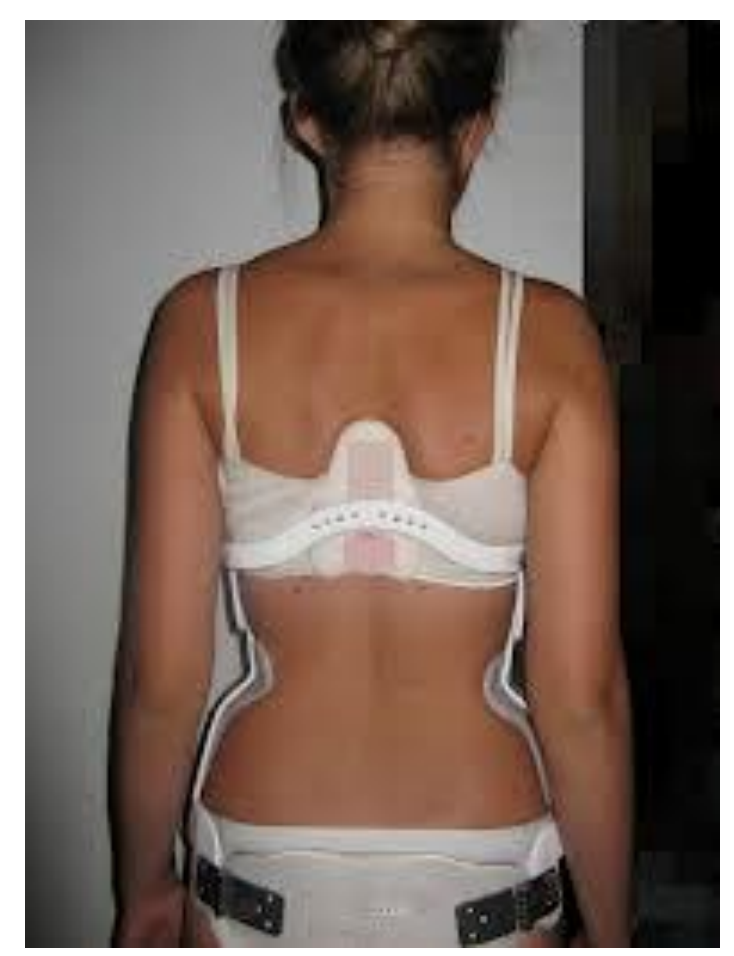

Figure 3. Gschwend brace ${ }^{9}$

Above 50 degree surgical consultation shall be needed. In case of a considerable deformity with large rotation the spine has to be stretched a few weeks before the operation. Under the operation surgeon lay a metal device onto vertebrae and connect it with the spine. This device removes weed curvatures and keep the spine in a fixed position. It is only suggested in case of a very serious disease. 


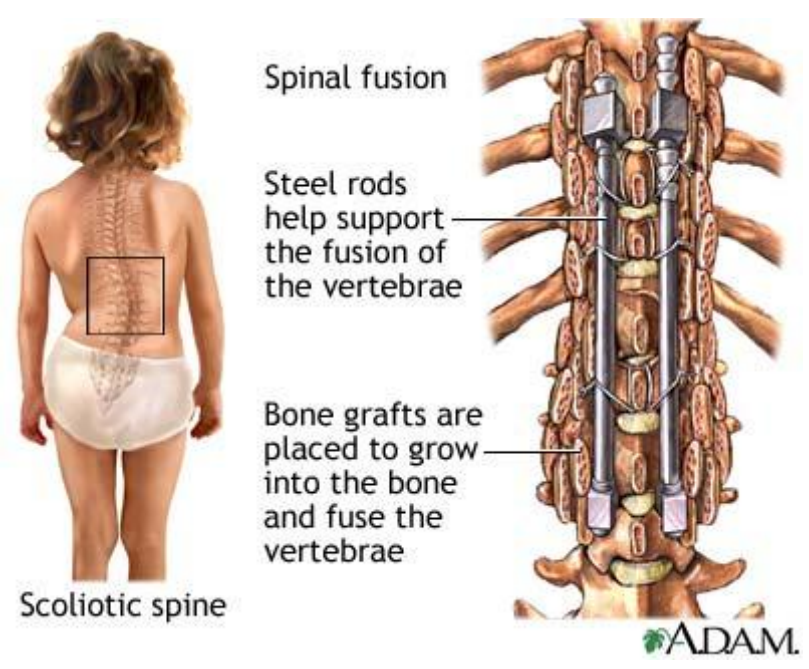

Figure 4. Spinal surgery 16

\section{Evaluating method}

With Kamal's method ${ }^{25}$ we can calculate the $\theta$ angle of the spinal curvature from moire images which correlates to Cobb angle in case of single curve scoliosis. The following points have to be used by this mathemathical method (according to Figure 5.):

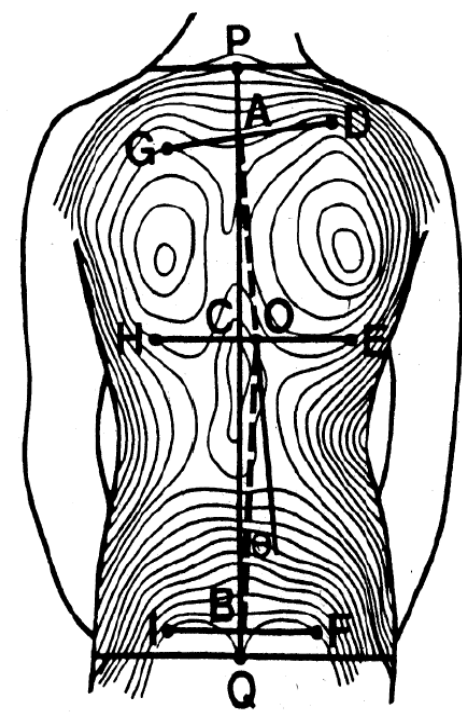

Figure 5. Measurement of the angle of spinal curvature by moiré topographs ${ }^{18}$

$$
\theta=\Varangle \mathrm{CAO}+\Varangle \mathrm{CBO}=\mathrm{Y} 1+\mathrm{Y} 2
$$

The $\mathrm{d} 1, \mathrm{~d} 2$ and $\mathrm{d} 3$ sections show the minimum asymmetry and can be given with the following equations where left to right direction is positive while right to left is negative: 


$$
\begin{aligned}
& \mathrm{d} 1=1 / 2^{*}(\mathrm{CH}+\mathrm{CE}) \\
& \mathrm{d} 2=1 / 2^{*}(\mathrm{AD}+\mathrm{AG}) \\
& \mathrm{d} 3=1 / 2^{*}(\mathrm{BF}+\mathrm{BI}) \\
& \tan Y 1=\frac{|\mathrm{a}| \mathrm{d} 1-\mathrm{d} 2|\square|}{\mathrm{CA}} \\
& \tan Y 2=\frac{|\mathrm{a}| \mathrm{d} 1-\mathrm{d} 3|\square|}{\mathrm{BC}}
\end{aligned}
$$

Kamal's algorithm to determine the points necessary for the calculations according to Figure 5. is as follows:

1. The midpoint of the neck $(\mathrm{P})$ have to be joined to the midpoint of the pelvis $(\mathrm{Q})$.

2. Find the moiré fringe on the scapula, which shows the most significant asymmetry, and intersect it with a line perpendicular to line PQ. So we can get points $\mathrm{H}, \mathrm{C}$ and $\mathrm{E}$.

3. Draw an upper tangent to the moiré fringe, which has been intersected by HE. This way we get points $G, A$ and $D$.

4. Finally, find a moiré fringe on the lumbar part of the spine, which is not significantly distorted, and intersect it with a line perpendicular to PQ. Points G, A and D can be defined this way.

Moiré images taken by us are used mostly to detect changes of patients' backs. The subjective evaluation by eyes can also show the changes. It is important to give psychical help for young children. Showing the result is always a good experience for them. This can give them willpower to continue the treatment. Otherwise decadence can be also challenging.

We found some conflicted cases, where the moire picture showed improvement, but X-ray images showed reverse results. It is planned to examine this problem, but at first very simple problems were choosen to be evaluated. Patients were selected with long thoracic curvature and minor rotation. The most often type of weed curvatures is a curve with right convex, long thoracic and left convex short lumbar part. Four patients were selected by us with similar deformity. We paid special attention to the perfect selection, the selected children's curves are very similar.

\section{Examinations}

The 4 selected children have at least two different X-ray photos, and two or more moiré pictures. 12 moiré pictures were evaluated. From moiré pictures approximate results were calculated. These results were compared with the Cobb angles calculated by orthopedic medicals from X-ray pictures. 
The evaluation and the measurements were done using RapidformXOR software. The height of the children and the zoom of the pictures were taken into consideration. The height of the patients were mesaured in the picture, and the measured height was scaled with the original height.
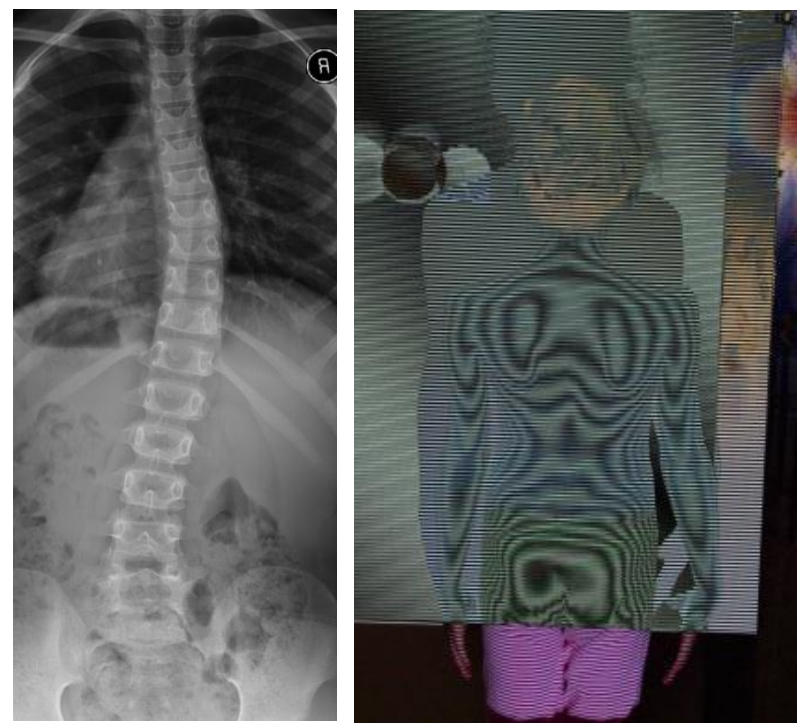

Figure 6. The first examined patient's moiré and X-ray images

The pictures were imported into the program, and the mentioned points were marked. Between the neck $(\mathrm{P})$ and the hips $(\mathrm{Q})$ a line was drawn to show the gradient of the spine. $\mathrm{G}, \mathrm{A}, \mathrm{D}, \mathrm{H}, \mathrm{C}$, $\mathrm{E}$ and I, B, F points were designated also.

The distances were measured and summarized in a table. The angles were calculated using Kamal's method and mathematical equations.

We wanted to try Kamal's method in use. The easiest deformity is the mentioned right convex long thoracic and left convex lumbar curvatures. It is easy to be perceived on the back. Kamal's method can be used, as the effect of the disease can be visible mostly in the middle of the back, under the scapulaes.

\section{Results}

Every selected patient has 3 moiré pictures. The first and the 3th images were taken at the same time as the X-rays, while middle moiré picture was compared to whichever X-ray image was taken at closer time to it.

The original Cobb angles - measured by orthopedic medicals - were compared with the calculated angles using the Kamal algorithm. I paired the results to be able to prepare a statistical evaluation. ${ }^{34-36}$

Average of medical measured Cobb angles was $30.4^{\circ}$. The average using the Kamal algorithm turned up $28.58^{\circ}$.

The standard deviation in the first case was 10.66, in the second case it was 10.95. 
Standard error was 3.078, after the evaluation of moiré pictures 3.161.

The original and the measured angles were stand in pairs, and paired t-test ${ }^{37}$ was applied. The $\mathrm{P}$ value was 0.2642 . It can be declared that there is no significant difference between the two methods, the evaluation of moiré images can give similar results as the other method.

The normal dispersion was checked with the Shapiro-Wilk test, $\mathrm{p}$ is not significant.

\section{Recommended Modification}

The first problem is that Cobb angles are measured on every weed curvature. If there is 2 or 3 weed curvatures on the spine, medicals measure 2 or 3 different values of them. Kamal algorithm is good for thoracic curvatures, but we haven't got data for other types of deformities. It is planned to examine other types of curvatures, like lumbar curvature and Scheuermann disease.

It is very important to have correct claibration and right settings before the measurement. The camera and the projector have to be perpendicular to the patient's back.

It is important to warn patient to stand in the right position, the picture has to be taken in time of total exhalation. We plane to use a handrail during taking the pictures to eliminate movement of the patients. It is important to have the pelvis in the correct position, length of legs have to be checked if it is necessary.

During the evaluation we have to pay attention to use the same contour lines, if it is possible.

\section{REFERENCES}

1. Theocaris PS. Moiré Fringe in Strain Analysis, Pergamon Press 1969.

2. Patorski K, Kujawinska M. Handbook of the Moire Fringe Technique, Elsevier, Amsterdam; 1993.

3. Durelli AJ, Parks VJ. Moiré Analysis of Strain, Prentice-Hall, Englewood Cliffs, New Jersey; 1970.

4. Parks VJ. Geometric Moiré, SEM Handbook of Experimental Mechanics, Prentice-Hall, Englewood Cliffs, New Jersey; 1987.

5. Parks VJ. Strain measurement using grids, Optical Engineering 1982;21::633-39.

6. Orosz M. Conservative treatment of the idiophatic scoliosis, Pediatrics 2005;56(6):651-57.

7. Adir IV, Wijk MC, Armstong WD. Moiré topography in scoliosis screening. Clin. Orthop., Clin. Orthop. 1977;129:165-71.

8. www.qualshare.com

9. http: //korzetteselet.blogspot.com

10. Chêneau J. Ein Weg zur richtigen Skoliosebehandlung. Orth. Tech., 4, 222, 1990.

11. Chêneau J. Das „original” Chêneau-Skoliosen-Korsett. Orth. Tech. Dortmund 1997.

12. Cobb JR. Outline for study of scoliosis. Am. Acad. Orthop. Surg. 5; 1948:261-6.

13. Orosz M. About the idiopathic scoliosis. Movement Therapy. 1; 2000:3-8.

14. Orosz M., Marlok F. The Chêneau brace. Rehabilitation. 1; 1997:10-11.

15. Orosz M. Structural failure of incorrectly prepared and used Cheneau braces in the treatment of scoliosis. Magyar Traumat. 2; 2000:83-90. 
16. www.healthcentral.com

17. Batouche M,Benlamri R, Kholladi MK. A computer vision system for diagnosing scoliosis using moiré images, Computers in Biology and Medicine, 1996;26(4):339-53.

18. Ruggerone M, Austin JHM. Moiré Topography in Scoliosis, Correlations with Vertebral Lateral Curvature as Determined by Radiography, Physical Therapy, 1986;66(7):1072-77.

19. Laulund T, Søjbjerg JO, Hørlyck E. Moiré Topography in School Screening for Structural Scoliosis, Acta Orthopaedica, 1982;53(5):765-68.

20. Windischbauer G. Survey on application of moire-techniques in medicine and biology. In Optics in Biomedical Sciences, Proceedings of the International Conference; Springer-Verlag Berlin; 1981:244-9

21. Takasaki H. Moiré Topgraphy, Applied Optics, 1970;9(6):1467-72.

22. Takasaki H. Moiré Topgraphy, Applied Optics, 1973;12(4):845-50.

23. Laulund T, Søjbjerg JO, Hørlyck E. Moiré Topography in School Screening for Structural Scoliosis, Acta Orthopaedica, 1982;53(5):765-8.

24. Wenzel K, Antal Á, Molnár J, Tóth B, Tamás P. New Optical Equipment in 3D Surface Measuring, Journal of Automation Mobile Robotics \& Intelligent Systems 2009;3(4):29-32.

25. Kamal SA. Determination of degree of correction of spinal deformity by moiré topographs, In. Moiré Fringe Topography and Spinal Deformity, Proceedings of the 2nd. International Symposium, Gustav Fischer Verlag, Stuttgart 1983. p. 117-26.

26. Neugebauer H. The different methods of measuring the curvature of scoliotic spineIn. Moiré Fringe Topography and Spinal Deformity, Proceedings of the 2nd. International Symposium, Gustav Fischer Verlag; Stuttgart 1983. p. 17-26.

27. Frontino G, Negri V, Rinaldi E. Photographic moiré method for preliminary diagnosis of spine deformity, Ateneo Parmense Acta Biomed. 1980;51(1):33-8.

28. Kim SH, Ishida K, Ishikawa S, Ohtsuka Y, Shimizu H. Discriminating spinal deformity employing centroids difference on the moiré images, Systems and Computers in Japan 32(7): 20-28.

29. www.healthtap.com

30. Gaal Zs, Antal Á, Péter T. Scoliosis testing features on the basis of electronically generated Moire patterns, Biomechanica Hungarica 2010;III(1):84-92.

31. Gaál Zs, Antal Á, Tamás P. Statiscical Analysis of Determining the Rate of Scoliosis from Electronically Generated Moire Patterns, In: Proceedings of Seventh Conference on Mechanical Engineering. Budapest; Hungary; 2010.05.25-2010.05.26 Budapest; 796-803.

32. Gaál Zs, Antal Á, Tamás P. Scoliosis Testing Features on the Basis of Electronically Generated Moire Patterns, In: 8th IEEE International Symposium on Applied Machine Intelligence and Informatics. 2010.01.28-2010.01.3; Herlany, Slovakia; 335-40.

33. Gaál Zs, Tamás P, Antal Á. Calibration and Measurement Test of Medical Moiré Equipment, In: XXIV. microCAD International Scientific Conference. Miskolc, Hungary; 2010.03.18-2010.03.20 Miskolc: Miskolci Egyetem Innovációs és Technológia Transzfer Centruma; ISBN: 978-963-661-919$0 ; 41-46$.

34. Gaál Zs, Antal Á, Tamás P. Statistical Analysis of Scoliosis Rate of Electronically Generated Moiré Images, In: IV. Hungarian Biomechanical Conference. Pécs, Hungary; 2010.05.07-2010.05.08; Paper A-0062.

35. Vincze I. Mathematical Statistics With Industrial Applications, Műszaki Kiadó; Budapest; 1968

36. Varga L. Introduction of the methods of didactic research, Tankönyvkiadó; Budapest; 1986

37. Kemény S, Deák A. Planning and evaluation of examinations, Műszaki Könyvkiadó; Bp.; 2000 
Conducting The research part of the tender called "Research of an intelligent device and method for observating and nursing orthopaedic deformities" (TECH_08-A1/2-20080121), specified by the Hungarian National Bureau of Research and Technology. 